\title{
Influence of volatile degassing on initial flow structure and entrainment during undersea volcanic fire fountaining eruptions
}

\author{
P. D. Friedman ${ }^{1 *}$, S. Carey $^{2}$, M. Raessi ${ }^{3}$ \\ ${ }^{1}$ University of Massachusetts Dartmouth, Dartmouth, USA; *Corresponding Author: pfriedman@umassd.edu \\ ${ }^{2}$ Graduate School of Oceanography, University of Rhode Island, Narragansett, USA; scarey@gso.uri.edu \\ ${ }^{3}$ University of Massachusetts Dartmouth, Dartmouth, USA; mraessi@umassd.edu
}

Received 23 October 2012; revised 25 November 2012; accepted 8 December 2012

\begin{abstract}
Release of dissolved volatiles during submarine fire fountaining eruptions can profoundly influence the buoyancy flux at the vent. Theoretical considerations indicate that in some cases buoyant magma can be erupted prior to fragmentation $(-75 \%$ vesicle volume threshold). Laboratory simulations using immiscible fluids of contrasting density indicate that the structure of the source flow at the vent depends critically on the relative magnitudes of buoyancy and momentum fluxes as reflected in the Richardson number (Ri). Analogue laboratory experiments of buoyant discharges demonstrate a variety of complex flow structures with the potential for greatly enhanced entrainment of surrounding seawater. Such conditions are likely to favor a positive feedback between phreatomagmatic explosions and volatile degassing that will contribute to explosive volcanism. The value of the Richardson number for any set of eruption parameters (magma discharge rate and volatile content) will depend on water depth as a result of the extent to which the exsolved volatile components can expand.
\end{abstract}

Keywords: Subaqueous Volcanism; Buoyant Eruption; Fragmentation; Submarine Fire Fountaining

\section{INTRODUCTION}

Interpreting the processes of submarine explosive eruptions has been difficult owing to the rarity of direct observations. Geological evidence suggests that submarine fire fountaining takes place in the marine environment based on the occurrence of fluidal breccias and highly vesicular basaltic clasts that show similarities to their subaerial counterparts [1]. Head and Wilson [2] have presented a comprehensive treatment of the theoretical considerations of submarine fire fountaining by exsolution of primary volatiles $\left(\mathrm{CO}_{2}\right.$ and $\left.\mathrm{H}_{2} \mathrm{O}\right)$. In their model they assume that fragmentation occurs when a gas volume fraction of 0.75 is attained by gas exsolution either within the conduit or right at the vent. An intriguing problem concerning submarine fire fountaining is to verify whether or not such an assumption is always valid. In subaerial eruptions, fragmentation typically occurs within the conduit or vent [3]. However, in the marine environment the hydrostatic pressure may be sufficient to inhibit bubble fragmentation until the magma has been discharged at the sea floor and rises to a depth where pressure is sufficiently reduced. This presents a potentially interesting phenomenon where a bubbly magma is erupted prior to fragmentation, but is buoyant relative to seawater, a condition that can never occur in the subaerial environment. If film boiling conditions sufficiently inhibit heat transfer, the flow structure may behave as an immiscible jet, plume or fountain. Subsequent mingling between discharged magma and seawater may provide an additional fragmentation trigger as a result of phreatomagmatic explosions and fundamentally control the nature of the subsequent eruption [4,5]. In this paper, we analyze the conditions that lead to positively buoyant discharges of vesiculated magma in submarine environments and discuss the potential implications for the entrainment of seawater and eruptive behavior based on some analogue experiments. We find that the initial flow structure of submarine eruptions is likely to vary significantly with water depth owing to the changes in buoyancy flux associated with the release of dissolved volatiles.

\section{BACKGROUND}

\subsection{Magma Buoyancy and Fragmentation}

Subaerial fire fountains consist of a spray of hot flui- 
dal clasts and gas ejected at velocities up to about a hundred meters/s forming spectacular fountains a few tens to several hundred meters above the vent [6]. The majority of clasts fall quickly back to the surface because a strong buoyantly convective phase is never fully developed and the fragmentation of clasts is relatively inefficient [7]. Accumulation of hot, fluidal clasts around the vent area produces distinctive spatter deposits that are characteristic of this type of activity. We suggest that complex behaviors of fire fountaining are possible in the submarine environment that would not occur under subaerial conditions. Such behaviors are related to the potential for having a positive buoyancy flux at the source vent of submarine basaltic fire fountaining eruptions.

Subaqueous eruptions of vesiculating magma will be positively buoyant if the bulk magma density $\left(\rho_{b}\right)$ is less than that of the surrounding seawater $\left(\rho_{s w}\right)$. The bulk density is a function of the mass fraction of exsolved volatiles $\left(x^{*}\right)$ (the mass fraction of volatiles that have separated from the solution), density of the exsolved volatile $\left(\rho_{v}\right)$ and the dense rock density $\left(\rho_{d r}\right)$.

$$
\rho_{b}=\left[\frac{\left(1-x^{*}\right)}{\left(1-x^{*}+x\right) \rho_{d r}}+\frac{x^{*}}{\rho_{v}}\right]^{-1}
$$

where $x^{*}$ depends on the total volatile mass fraction $(x)$ and the solubility of the volatile component in the magma $\left(x_{s}\right)$,

$$
x^{*}=\left\{\begin{array}{cc}
x-x_{s}, & x>x_{s} \\
0, & x_{s}>x
\end{array} .\right.
$$

The soluble limit for a given volatile component and magma composition is a function of pressure and temperature

$$
x_{s}=f(P, T) \text {. }
$$

We have evaluated conditions of magma buoyancy using the VolatileCalc 1 program to calculate gas solubilities [8]. For $\mathrm{CO}_{2}$, the density was calculated using the ideal gas law and in the case of water, the density of the exsolved component (steam) was taken from tabulated data (ASME Steam tables). As a result of surface tension $(\sigma)$, the pressure within a gas bubble exceeds the pressure of the surrounding fluid $(P)$,

$$
P^{*}=P+4 \sigma / d
$$

where $d$ is the void diameter. For non-spherical bubbles the diameter is calculated from a major and minor axis, $d=2 /\left(1 / d_{1}+1 / d_{2}\right)$. For simplicity in our calculations we have assumed that the pressure in the bubbles is equal to that of the ambient pressure and ignored this surface tension effect, which requires a detailed knowledge of bubble size and the complex interfacial tension relationship.

Bubbly suspensions of uniformly sized bubbles can commonly exist up to a gas volume fraction of 0.85 before fragmentation [9] and a fragmentation limit of about 0.75 is often cited based on observations of natural subaerial samples [10-12]. However, recent experimental work has identified a critical overpressure necessary to fragment magma that is a function of porosity and permeability [13,14]. Fragmentation can occur at gas volumes significantly below 0.75 , but requires relatively high levels of overpressure, especially if the magma has high permeability. At exsolved gas volumes of 0.75 a critical overpressure of about $2-3 \mathrm{MPa}$ is required to fragment magma into low pressure atmospheric conditions. This required overpressure is likely the result of the tensile strength of the melt phase and the interfacial tension noted above. In submarine eruptions the presence of hydrostatic pressure at the vent should inhibit magma fragmentation relative to subaerial eruptions. For example, the ambient pressure at only $200 \mathrm{~m}$ water depth is 2 $\mathrm{MPa}$, or similar to the required overpressure necessary to fragment magma with gas volume fraction of 0.75 . In our calculations we have used the 0.75 fragmentation limit with the caveat that this limit may potentially be higher in submarine events.

Simple degassing calculations using the equations cited above demonstrate that it is possible for basaltic magma that is vesiculating to attain positive buoyancy relative to seawater prior to reaching gas volume fractions commonly associated with fragmentation (75\%). Figure 1 shows the vesicularity for a $1200^{\circ} \mathrm{C}$ basaltic magma as a function of water content and depth. The dashed line "Positive Buoyancy" is the minimum vesicularity required to have a net upward buoyant force on the magma. The slight positive slope of this line results from the density increase of the volatile phase with increasing water depth. The solid line assumes that fragmentation occurs at $75 \%$ vesicularity. Thus the band between these two lines represents a zone of positively buoyant unfragmented magma. Consider $1200^{\circ} \mathrm{C}$ basaltic magma with a $2 \%$ water content. At a depth of 1000 meters it would be positively buoyant, but would not reach the fragmentation point until a depth of $700 \mathrm{~m}$. The results indicate that magmas with higher volatile contents have a larger depth range over which they are buoyant but still not at the fragmentation threshold. Unfragmented magma with $4 \%$ water, for example, could exist at depths of 1600 to 2500 meters.

The range of volatile contents that we evaluated in Figure $1(1 \%-4 \%)$ is higher than most juvenile water contents associated with basaltic magmas [15]. However, recent discoveries of deep water basaltic explosive volcanism has led to the suggestion that pre-concentration of volatiles prior to eruption may be an important process in driving gas contents high enough to support explosive 




Figure 1. Variation in the vesicularity of magmas with volatile contents from $1 \%$ to $4 \%$ water as a function of water depth for $1200^{\circ} \mathrm{C}$ magma. The typical fragmentation vesicularity of $75 \%$ is shown along with the vesicularity value where magma above which magma is buoyant relative to seawater. The positive buoyancy vesicularity increases slightly with depth as the result of an increasing density of the gas phase at higher pressures.

fragmentation in the submarine environment [2,16]. Thus submarine fire fountaining may be driven by volatile contents higher than those typically associated with the primary gas content of seafloor basalts.

\subsection{Hydrodynamic Background}

Subaqueous eruption of magma differs significantly from subaerial conditions owing to the difference in density of the ambient environment into which magma is discharged and the dramatic variations in the rate of heat exchange between magma and water versus magma and air. Under film boiling conditions, an insulating vapor blanket develops between molten magma and surrounding seawater, greatly suppressing heat transfer. As a result, a reasonable first order approximation is to analyze the hydrodynamic flow structure as decoupled from heat transfer until fragmentation occurs. A vertically-directed immiscible discharge is governed by the functional relationship [17]:

$$
\left(S t, \frac{h}{D}, B o\right)=F\left(R i, R e, W e, \phi, \frac{\mu_{b}}{\mu_{a}}\right)
$$

where:

$$
S t=\frac{f D}{U} \quad B o=\frac{\mathrm{d}^{2} g\left(\rho_{s w}-\rho_{b}\right)}{\sigma}
$$

\footnotetext{
${ }^{1}$ In previous papers regarding negatively buoyant fountains and jets we defined the Richardson number as positive in the negatively buoyant case. In this paper where we are concerned with both positive and negatively buoyant discharges, we have adopted a sign convention that Richardson number is positive for positively buoyant flows.
}

$$
R i=\frac{D g\left(\rho_{s w}-\rho_{b}\right)}{\rho_{b} U^{2}} \quad R e=\frac{\rho_{b} U D}{\mu_{b}} \quad W e=\frac{\rho_{b} U^{2} D}{\sigma}
$$

Here, $D$ is the vent diameter; $U$ is the vent exit velocity; $h$ is the characteristic height in flow structure; $\phi$ is the vent geometry parameter; $d$ is the characteristic mingling void size; $\mu_{b}, \mu_{a}$ are the bulk and ambient viscosities, respectively; $\sigma$ is the interfacial tension between discharged and ambient fluids and $f$ is the characteristic frequency of the flow structure.

The dependent Strouhal number $(S t)$ represents a dimensionless characteristic frequency of the flow structure. In the case of a negatively buoyant fountain, $S t$ is the frequency at which the fountain collapses and reforms [18]. The Bond number $(B o)$ is the dimensionless size of the mingling between the phases [19] and $h / D$ is the dimensionless characteristic height of the flow structure. In the case of a negatively buoyant fountain or jet, $h / D$ is the maximum height of rise of the flow structure [20]. The independent Richardson number $(R i)$ is the ratio of the buoyant forces to the inertial forces ${ }^{1}$. As will be discussed below, $R i$ is the dominant parameter in determining the flow structure. Reynolds number $(R e)$ is the ratio of the inertial to the viscous forces. Weber number $(\mathrm{We})$ is the ratio of the inertial forces to the interfacial tension forces of the overall vent structure. In the case of volcanic eruptions, $W e \rightarrow \infty$. The other independent parameters are a discharge vent shape parameter and the viscosity ratio between the discharged and ambient fluid. The bulk viscosity of the magma is dependent on the Capillary number of the magma [21]. In general, at high capillary numbers $\gg 1$ 
where viscous forces dominate, the viscosity decreases with increasing vesicularity.

\section{LABORATORY EXPERIMENTS}

Our analysis of submarine eruption processes draws on experimental results performed on negatively buoyant fountains and jets that were previously reported in $[17,18]$ and additional experiments conducted on positively buoyant jets and plumes. The equipment and procedures, which are briefly described here, are more thoroughly discussed in $[17,18]$. The experimental setup (Figure 2) consisted of a $30.5(\mathrm{~L}) \times 30.5(\mathrm{~W}) \times 40 \mathrm{~cm}(\mathrm{H})$ test chamber, a circulating pump loop and an illumination and data acquisition system. The circulating loop drew the fountain fluid from a reservoir at the bottom or top of the test facility, depending on whether negatively or positively buoyant cases were being investigated and pumped it through a throttle valve and flow meter to the vent assembly in the test chamber. Vent geometries included a convergent nozzle, cylindrical pipes with diameters ranging from $1.9 \mathrm{~cm}$ to $3.8 \mathrm{~cm}$ and a rectangular geometry. The facility was illuminated using the beam of a New Wave Research dual-head, Solo 30 PIV Nd:YAG passed through a pair of cylindrical lenses that form a light sheet and a spherical lens that controlled the light sheet thickness. Digital images were captured using a TSI Model\# 630057 PowerView plus 2 Megapixel digital CCD camera. When permitted by index matching [17] and fluid clarity, the fluid flow structure was analyzed using TSI Insight 6 particle image velocimetry (PIV) Software.
Sample images for positively and negatively buoyant discharges are shown in Figure 3. A negatively buoyant fountain occurs when negative buoyancy dominates (nominally $R i<-1$ ). The flow structure is characterized by stable smooth flow structure without phase mingling. As inertial forces are increased (nominally $0>R i>-1$ ) a negatively buoyant jet develops and the rise height increases to the point where an unsteady flow structure repeatedly collapses and reforms. Positively buoyant jets $(0<R i<1)$ are dominated by inertia, whereas plumes are dominated by positive buoyancy. Oscillating plumes narrow as buoyancy accelerates the flow, which subsequently develops a sinusoidal shape that oscillates in a radial pattern and then breaks apart. Blob plumes break apart at the vent with a characteristic dimension on the order of the size of the vent. Finally atomized plumes break immediately apart with a characteristic dimension that is small in comparison to the vent diameter.

In the case of negatively buoyant eruptions, $R i$ is overwhelmingly the dominant independent parameter of Eq.1 with specific flow behaviors associated with certain threshold values [18]. For $R i<-1.0$, a smooth stable fountain forms; while for negative Richardson numbers above this threshold, a distinct transition occurs in which an unstable negatively buoyant jet alternately collapses and reforms [18]. This instability causes phase mingling. The nominal $R i=-1$ transitional Richardson number is slightly altered by varying Reynolds number $(R e)$, Weber number $(W e)$ and viscosity ratio [17]. Most of the $R e$ effect can be accounted for by defining a corrected Richardson number $\left(R i_{C}\right)$ in terms of a root mean
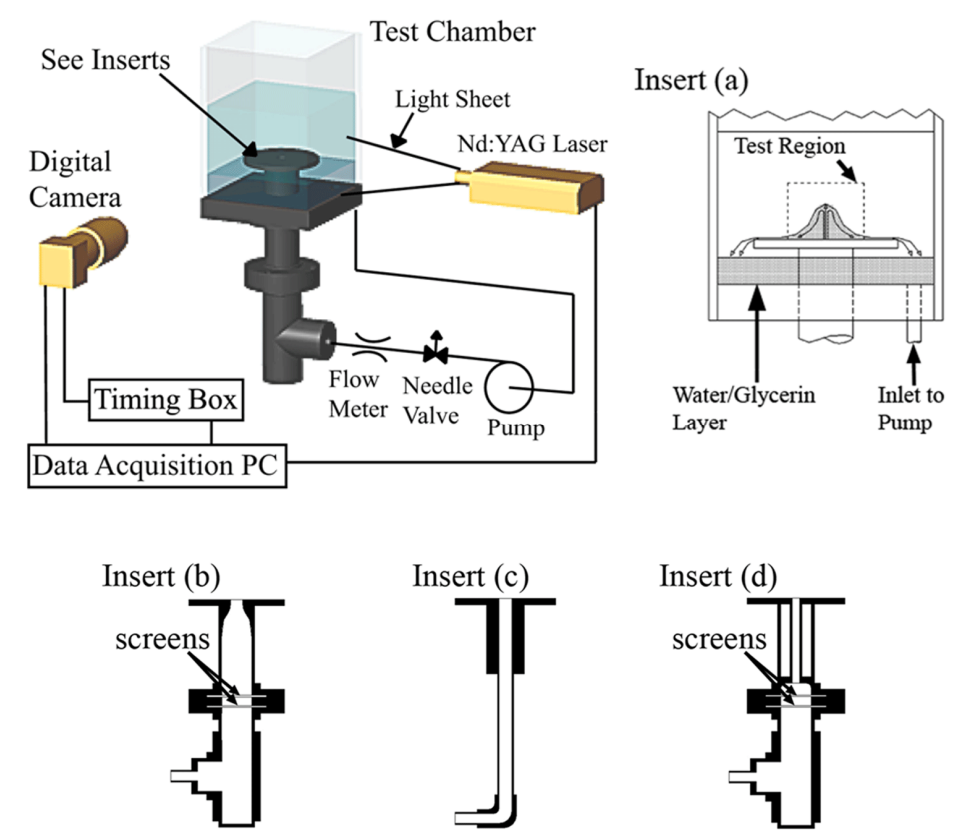

Figure 2. Experimental setup. For positively buoyant experiments, suction was drawn from above the interface. 


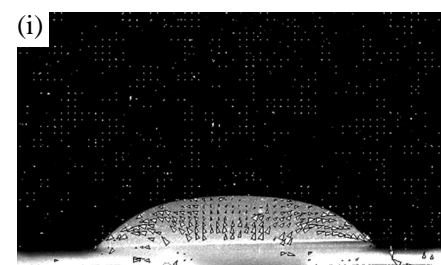

$\mathrm{Ri}=-3$ Fountain

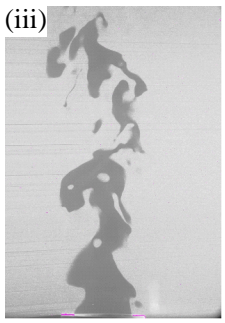

$\mathrm{Ri}=0.8$

Positively Buoyant Jet



$\mathrm{Ri}=10$

Oscillating Plume

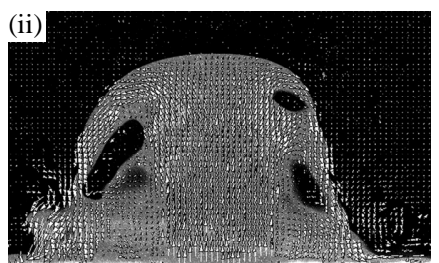

$\mathrm{Ri}=-0.5$ Negatively buoyant Jet

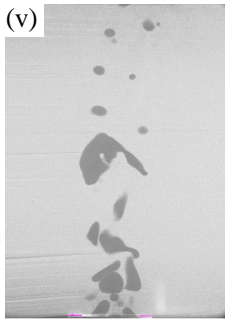

$\mathrm{Ri}=50$

Blob Plume



$\mathrm{Ri}=100$

Atomized Plume

Figure 3. Experimentally recorded images of the flow structures for positively and negatively buoyant fountains, jets and plumes. Silicone oil is used for the lighter fluid and a glycerin/water mixture that is mixed in proportion.

square average velocity to account for the increased momentum of laminar flows. Interfacial surface tension stabilizes the interface and leads to a trend of decreasing transitional $R i_{C}$ with increasing $W e_{C}$ (corrected Weber number defined similarly to $R i_{C}$ ). Although the effect is relatively minor, viscosity ratios deviating from unity stabilize the interface leading to a trend of a minimum transitional $R i_{C}$ for viscosity ratios of 1.0. Results for noncircular vents are consistent with the data for cylindrical exits if flow parameters are defined in terms of the hydraulic diameter.

The positively buoyant images shown in Figure $\mathbf{3}$ are illustrative of the types of potential flow structures from preliminary experiments that were performed without individually controlling for the effects of $R e$, Viscosity ratios, and We. Despite this limitation the results point to a variety of complex flow structures in which the two fluids exhibit enhanced mingling relative to the negatively buoyant collapsing fountains. Such mingling is likely critical to achieving the necessary pre-mixing conditions for phreatomagmatic interactions that could provide a positive feedback to fragmentation associated with primary volatile degassing [22].

While the experimental results demonstrate that the Richardson number is the dominant parameter (with Reynolds number, viscosity ratio and Weber number providing relatively minor contributions in the range of parameters investigated), it is impossible to match the broad range of viscosity ratios and Reynolds numbers that potentially occur in actual eruptions. The viscosity of basaltic magma can range from $10^{2}$ to $10^{4}$ poise. In addition, the bulk viscosity can vary greatly as a result of entrained bubbles, depending on the Capillary number
[23].

\section{NUMERICAL SIMULATIONS}

In order to further investigate the nature of potential submarine flow structures we used an in-house flow solver called NGA [24-26] to perform numerical simulations of positively buoyant discharges. NGA is designed for simulations of turbulent multiphase flows. Using a consistent mass and momentum transport scheme [27], NGA can handle simulations of multiphase flows with arbitrary large density ratios. NGA solves turbulent flows using either direct numerical simulation (DNS) or large eddy simulation (LES) approaches and has been carefully validated [24-27] using several canonical test cases.

The governing equations for a multiphase flow of Newtonian immiscible fluids are conservation of mass and momentum

$$
\begin{gathered}
\frac{\partial \rho}{\partial t}+\nabla \cdot(\rho U)=0 \\
\frac{\partial(\rho U)}{\partial t}+\nabla \cdot(\rho \mathbf{U U})=-\nabla p+\nabla \cdot \tau+\mathbf{F}_{B}+\mathbf{F}_{S T}
\end{gathered}
$$

where $\mathbf{U}$ denotes velocity, $p$ pressure, $\tau$ the shear stress tensor $\tau=\mu\left(\nabla \mathbf{U}+\nabla \mathbf{U}^{T}\right), \mathbf{F}_{B}$ body force (e.g. gravity), and $\mathbf{F}_{S T}$ is the surface tension force.

NGA is a parallel, finite-difference, structured, flow solver with staggered arrangement of variables. It employs the projection method to solve the governing equations in which the temporal integration is done using an iterative, second-order, Crank-Nicolson formulation. A single set of governing equations is solved in the whole numerical domain for simulations of multiphase flows, 
where the spatial terms are discretized with second-order accurate schemes. At any point in the domain, the fluid properties, namely density $\rho$ and viscosity $\mu$ are determined by a scalar indicator function $G$ (described below). To incorporate jump conditions across fluid interfaces, the Ghost Fluid method (GFM) [25,28] is employed.

To model the kinematics and deformation of fluid interfaces, a special type of the level set method, known as the spectrally refined interface (SRI) method [26] is used. As demonstrated by Desjardins \& Pitsch [26], SRI exhibits excellent accuracy in modeling complex interface kinematics as well as mass-conservative properties. In this method, the following transport equation for a scalar indicator function $G=G(\mathbf{x}, t)$ is solved using a semiLagrangian approach [26]:

$$
\frac{\partial G}{\partial t}+\mathbf{U} \cdot \nabla G=0
$$

Although $G$ can be any smooth function, we use a signed distance function here, so the interface is represented by an iso-surface $G_{0}=0$.

Figure 4 shows the results of numerical simulations of positively buoyant discharges at two Richardson numbers $R i=1$ and 10 . There are 80 grid points across the jet thickness. Comparing to the experimental results (Figure 3), we see that the key features are captured very well in our preliminary simulations. As the figure shows, at low Richardson numbers $R i=1$, the jet is inertia driven and rollups and skirts are formed as the jet rises because of shear force exerted by the surrounding fluid. Increasing the Richardson number to $R i=10$ forms an oscillating jet/plume similar to the experimental result shown in Figure 3, where the breakup now occurs closer to the vent exit.

\section{GEOLOGIC ANALYSIS}

Here we consider the effects of water depth on the po-
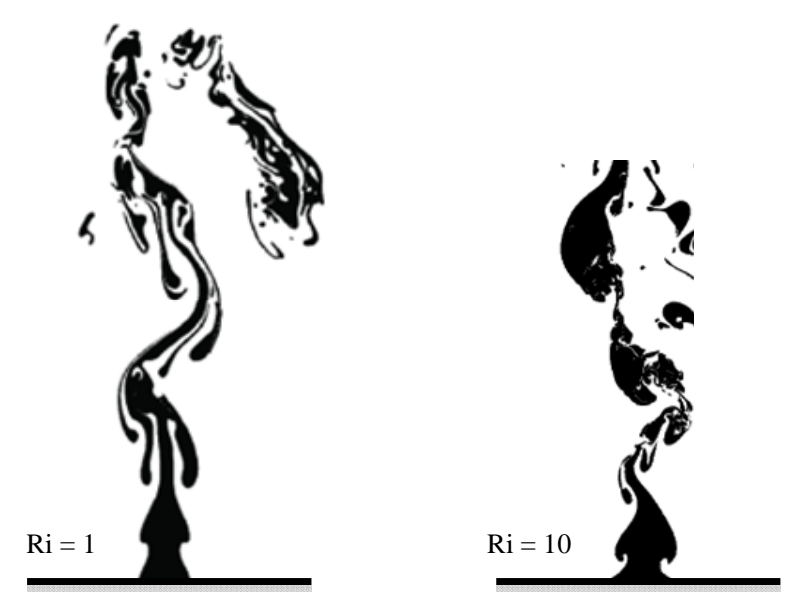

Figure 4. 2D numerical simulation of positively buoyant discharges at Richardson numbers 1 and 10. tential style of submarine basaltic fire fountaining eruptions as a result of its influence on the bulk density of the initial erupting mixture (degassing). As a baseline eruption, we have chosen a discharge rate of $200 \mathrm{~m}^{3} / \mathrm{s}$ of dense rock equivalent similar to magma discharge associated with subaerial fire fountaining events [29]. Additionally, the baseline eruption assumes $1200^{\circ} \mathrm{C}$ magma, containing $2 \%$ water content, with discharge from a 10 meter circular vent. Assuming fragmentation occurs at $75 \%$ vesicularity, the discharge would consist of a twophase liquid with suspended bubbles at a depth greater than 700 meters and a two-phase gas with suspended liquid at shallower depths (Figure 1).

As shown in Figure 5, at very shallow conditions (10 meters), the bulk density is $18.4 \mathrm{~kg} / \mathrm{m}^{3}$, yielding a Richardson number of 0.03 and these conditions would favor energetic fragmentation by volatile degassing. As depth is increased, the reduction in specific volume of the gas phase causes a decrease in velocity and buoyancy. Initially, the dominate effect is the velocity reduction causing the Richardson number to increase. In the baseline case, buoyancy does not increase sufficiently for a transition to plume behavior. The maximum Richardson number is reached at 500 meters, below which the dominant effect on increasing depth is a reduction in buoyancy. At a depth of 1000 meters, the flow becomes negatively buoyant and the flow structure transitions into a negatively buoyant jet. At a depth of $1400 \mathrm{~m}, R_{i}<-1$ and the flow transitions to a stable collapsing fountain. Figure 5 also shows the effect of varying water concentration from $0 \%$ to $4 \%$. With no volatile constituents, the resultant Richardson number would be -9.2 (the dashed horizontal line), regardless of depth, indicating a stable fountain without phase mingling. With higher discharge rates, the volatile-free line moves upward making mingling possible, even without the presence of volatiles [18]. Each of the curves representing various concentrations of water turns abruptly horizontal at the depth that it reaches the zero volatiles horizontal line. As the concentration of exsolved volatiles increases at shallow depths, the velocity increases resulting in a reduction of Richardson number. An increasing concentration of volatiles increases the depth at which phase mingling can be expected. With $4 \%$ water, the fragmentation vesicularity (75\%) would occur at a depth of 1400 meters. Positive buoyancy would exist down to a depth of 2200 meters and the mingling threshold of $R i=-1.0$ would occur at a depth of about 3500 meters. In comparison to water, $\mathrm{CO}_{2}$ has a much lower increase in solubility with pressure, leading to shallower slopes of the Richardson number curves (Figure 6). Temperature changes of the magma have a slight effect by changing the buoyancy (not shown).

Vent diameter and flow rate have no effect on the tran- 




Figure 5. Effect of volatile concentration on Richardson number as a function of water depth. The baseline event is an eruption of 200 cubic meter/s of dense rock equivalent, containing $2 \%$ water content at $1200^{\circ} \mathrm{C}$ discharging from a 10 meter vent. Under volatilefree conditions, the Richardson number is independent of depth of the vent as seen by the curve labeled "No Volatiles". Where the each of the curves intersect the no volatiles curve, the pressure is sufficient to hold all volatiles in solution. The curves all bend sharply bend sharply to the right at this point.

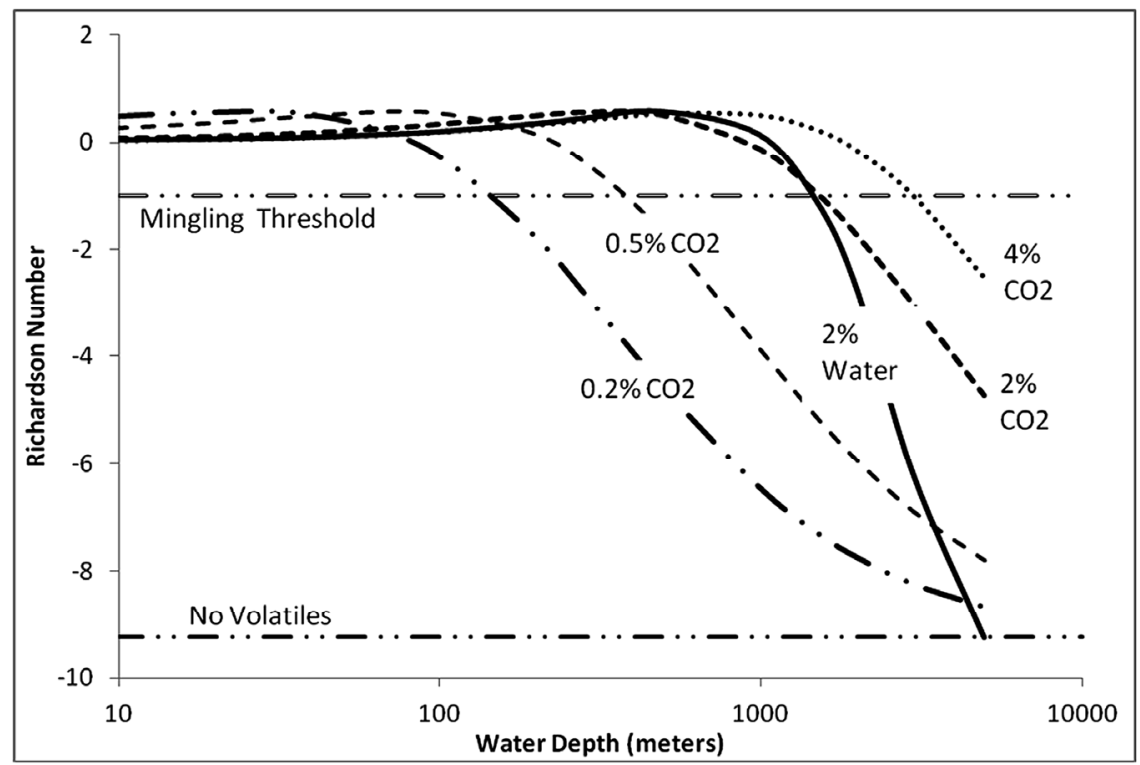

Figure 6. Effect of $\mathrm{CO}_{2}$ on Richardson number. At shallow depths, the effect if $\mathrm{CO}_{2}$ is comparable to water. However as pressure increases, the increased solubility of water diminishes its effect.

sition from positive to negative buoyancy (the sign of $R i$ ), but greatly affect the magnitude (Figures 7 and 8 ). As previously shown, the baseline case never behaves as a plume as a result of the high inertial forces. A reduction in flow rate to $50 \mathrm{~cm} / \mathrm{s}$ results in a flow that has little chance of mingling at depths in which it is negatively buoyant and it behaves as a plume at most depths in which it is positively buoyant, excepting very shallow eruptions (less than about 20 meters). Likewise increasing the vent diameter has a similar effect. 


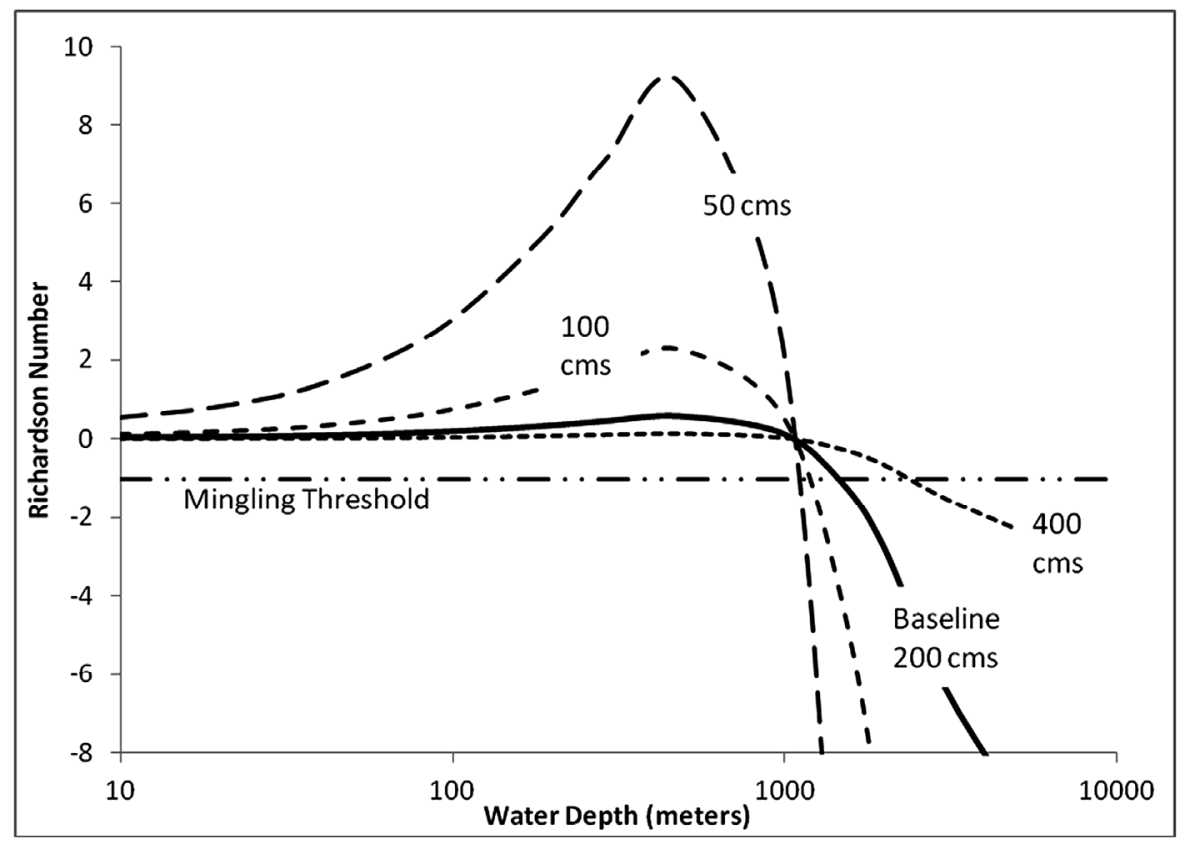

Figure 7. Effect of flow rate, indicated in cubic meters per second (cms), on Richardson number. The flow rate has no effect on the depth at which the flow becomes positively buoyant $(R i=0)$; however, increasing flow rate increases the inertia and causes absolute value of all Richardson numbers to decrease. As the flow rate increases, the depth at which phase mingling potentially occurs increases.

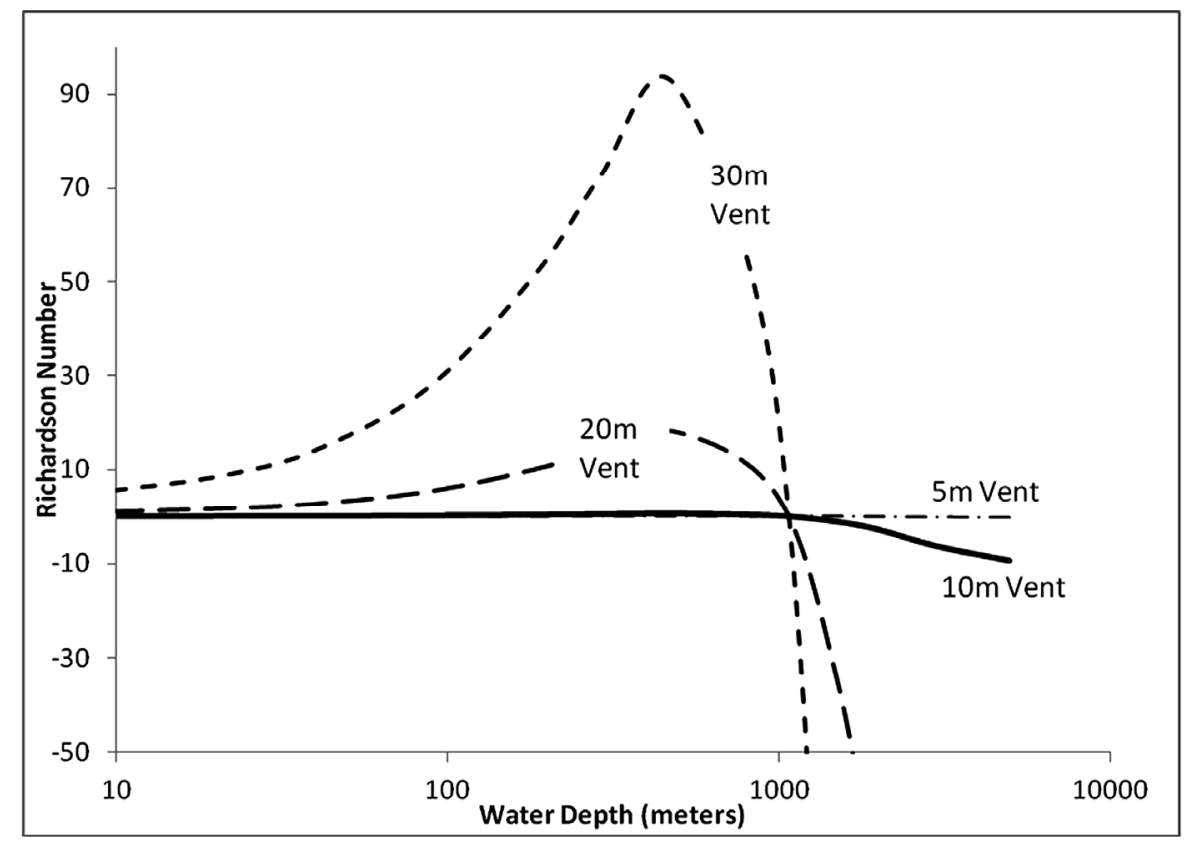

Figure 8. Effect of vent diameter on Richardson number. The effect of decreasing vent diameter is similar to increasing the flow rate (see Figure 7).

Figure 9 maps the effect of water content, depth and flow rate on the expected flow conditions for $1200^{\circ} \mathrm{C}$ magma. The curve labeled "Positive Buoyancy Threshold" shows the water content as a function of depth that is necessary for the eruption to be positively buoyant.
Eruptions falling along this curve will have a Richardson number equal to zero, regardless of flow conditions (vent size and eruption rate). The water content associated with $75 \%$ vesicularity (the nominal fragmentation threshold) is also shown as a function of water depth. Under film 




Figure 9. Summary map showing the effect of water content, depth and flow rate for $1200^{\circ} \mathrm{C}$ magma. Mingling thresholds are indicated in cubic meters per second (cms) for a 10 meter diameter vent.

boiling conditions where heat transfer is suppressed, the region below this curve will potentially be un-fragmented bubble-laden magma. Eruptions between the neutral buoyancy and $75 \%$ vesicularity could rise under buoyant forces until either they reach a depth where vesicularity is high enough to cause fragmentation. Another possibility is that they would erupt under conditions in which the flow caused phase mingling, which in turn triggered fragmentation. The figure also shows mingling thresholds for a ten meter diameter vent, assuming that phase mingling occurs at $R i=-1$. As demonstrated, increasing eruption rates decrease the water content necessary to reach the threshold. A flow rate of about 600 $\mathrm{m}^{3} / \mathrm{s}$ coincides with the horizontal axis-meaning that at $600 \mathrm{~m}^{3} / \mathrm{s}$, phase mingling occurs without the presence of water.

\section{DISCUSSION}

Our experimental results demonstrate that the potential structure of a submarine eruption discharge can take dramatically different forms, such as fire fountaining or passive effusive discharges, depending on the relative contributions of momentum and buoyancy at the source vent. Unlike subaerial eruptions where bulk density of the erupting mixture is always greater than the ambient environment, submarine eruptions can discharge vesiculating magma that is less dense than surrounding seawater and lead to positive buoyancy flux. The bulk density of the erupting mixtures is determined by the gas content of the magma and the depth of the eruption. Thus, magmas with similar gas contents can produce greatly contrasting discharge structures depending on the water depth of the eruption.

The complicated structures of discharges with positive buoyancy (Figure 3) illustrated by the experiments, suggests a mechanism for the production of coarsely fragmented spatter-like deposits that have been attributed to submarine fire fountaining. Discharges of gas-rich basaltic magma could generate positively buoyant plumes of vesiculated magma that break up into coarse parcels. This would facilitate interaction with seawater and a rapid change of clast density by quenching of steam within accessible vesicles. Allen et al. [30] have shown that buoyant, vesiculated magma that comes in contact with seawater can transition to negative buoyancy relatively quickly due to the quenching of steam to water that generates negative pore pressures. However, clasts may still be able to retain sufficient heat to deform in a plastic manner and produce deformed clasts that have been attributed submarine fire fountaining under submarine conditions.

The potential for erupting buoyant magma in the submarine environment and the subsequent complex jet structure could also explain an unsual submarine basaltic eruption that took place off of Soccorro island, Mexico [31]. In 1993 submarine vents at depths up to 210 meters discharged highly vesiculated basalt that rose to the surface as large 1 - 3 meters blocks. Many blocks consisted of reticulite with porosities of $98 \%$ [31]. Some clasts also included denser scoriaceous zones with mean porosities of $67 \%$. Such products would have contributed to significant buoyancy flux at the vent within the observed 
depth ranges of the eruptions and could have produced a discharge of initially unfragmented bubbly magma that then coarsely mixed with seawater and broke up into large clasts. The largest clasts that reached the surface were big enough such that their interaction with seawater was not sufficiently rapid to cause a transition to negative buoyancy before they were able to rise to the surface. Timescales of transitions to negative buoyancy of vesiculated magma exposed to water is dependent on clast size [32]. In the case of the Soccorro eruption, once the large clasts reached the surface they continued to interact with seawater, generating steam jets that propelled the clasts over the sea surface until they eventually absorbed enough water to sink [31].

The results of our analogue experiments also bear on the mechanism of phreatomagmatic eruptions in the submarine environment. Büttner and Zimanowski [22] found that mingling of magma and water is critical to achieving the necessary pre-mixing conditions for phreatomagmatic explosions that could provide a positive feedback to fragmentation associated with primary volatile degassing. The discharge structure of the buoyant immiscible plumes indicates that convoluted flow and breakup would facilitate pre-mixing of magma and water on a number of scales. Whether phreatomagmatic explosions would be triggered depends on the water depth at which the interactions occurred.

\section{CONCLUSION}

Submarine fire fountain eruptions possess the unique capability of erupting positively buoyant magma relative to the surrounding environment. Experimental results indicate that the structure of the source flow at the vent depends critically on the relative magnitudes of buoyancy and momentum fluxes as reflected in the Richardson number $(R i)$. A theoretical consideration of the submarine eruption of degassing magma indicates that in some cases buoyant magma can be erupted prior to fragmentation. Analogue laboratory experiments of these conditions demonstrate a complex flow structure with the potential for greatly enhanced entrainment of surrounding seawater. We suggest that such conditions are likely to favor a positive feedback between phreatomagmatic explosions and volatile degassing that will contribute to highly explosive volcanism. The value of the Richardson number for any set of eruption parameters (magma discharge rate and volatile content) will depend on water depth as a result of the extent to which the exsolved volatile components can expand. Thus there will be critical ranges of water depth over which specific eruption styles (explosive versus non-explosive) can occur depending on the initial volatile content, magma viscosity, and discharge rates of the source eruptions.

\section{REFERENCES}

[1] Simpson, K. and McPhie, J. (2001) Fluidal-clast breccia generated by submarine fire fountaining, Trooper Creek Formation, Queensland, Australia. Journal of Volcanology and Geothermal Research, 109, 339-355. doi:10.1016/S0377-0273(01)00199-8

[2] Head, J.W. and Wilson, L. (2003) Deep submarine pyroclastic eruptions: Theory and predicted landforms and deposits. Journal of Volcanology and Geothermal Research, 121, 155-193. doi:10.1016/S0377-0273(02)00425-0

[3] Mader, H. (1998) Conduit flow and fragmentation. In: Gilbert, J.S. and Sparks, R.S.J., Eds., The Physics of Explosive Volcanic Eruptions, Geological Society London Special Publications, London, 51-71.

[4] Kokelaar, B.P. (1986) Magma-water interactions in subaqueous and emergent balasatic volcanism. Bulletin of Volcanology, 48, 275-289. doi:10.1007/BF01081756

[5] Wohletz, K.H. (2003) Water/Magma interaction: Physical considerations for the deep submarine environment. In: White, J.D.L., Smellie, J. and Clague, D., Eds., Explosive Subaqueous Volcanism, American Geophysical Union, Washington DC, 25-50. doi:10.1029/140GM02

[6] Parfitt, E. and Wilson, L. (2008) Fundamentals of physical volcanology. Blackwell Publishing, Oxford.

[7] Sparks, R.S.J., Bursik, M., Carey, S.N., Gilbert, J., Glaze, L., Sigurdsson, H. and Woods, A. (1997) Volcanic plumes. Wiley, Chichester.

[8] Newman, S. and Lowenstern, J.B. (2002) VolatileCalc: A silicate melt $-\mathrm{H}_{2} \mathrm{O}-\mathrm{CO}_{2}$ solution model written in visual basic for Excel. Computers and Geosciences, 28, 597604. doi:10.1016/S0098-3004(01)00081-4

[9] Cashman, K. and Mangan, M. (1994) Physical aspects of magmatic degassing. In: Carroll, M. and Holloway, J., Eds., Volatiles in Magmas-Reviews in Mineralogy, Mineralogical Society of America, Chantilly, 447-478.

[10] Sparks, R.S.J. (1978) The dynamics of bubble formation and growth in magmas-A review and analysis. Journal of Volcanology and Geothermal Research, 3, 1-17. doi:10.1016/0377-0273(78)90002-1

[11] Sparks, R.S.J., Barclay, J., Jaupart, C., Mader, H.M. and Phillips, J.C. (1994) Physical aspects of magmatic degassing. I. Experimental and theoretical constraints on vesiculation. In: Carroll, M.R. and Holloway, J.R., Eds., Volatiles in Magmas, Mineralogical Society of America, Chantilly, 413-445.

[12] Gardner, J., Thomas, R., Jaupart, C. and Tait, S. (1996) Fragmentation of magma during plinian volcanic eruptions. Bulletin of Volcanology, 58, 144-162. doi:10.1007/s004450050132

[13] Spieler, O., Kennedy, B., Kueppers, U., Dingwell, D., Scheu, B. and Taddeucci, J. (2004) The fragmentation threshold of pyroclastic rocks. Earth and Planetary Science Letters, 226, 139-148. doi:10.1016/j.epsl.2004.07.016

[14] Mueller, S., Scheu, B., Spieler, O. and Dingwell, D. (2008) Permeability control on magma fragmentation. Geology, 36, 399-402. doi:10.1130/G24605A.1

[15] Dixon, J.E., Stolper, E. and Delaney, J. (1988) Infared 
spectroscopic measurements of $\mathrm{CO}_{2}$ and $\mathrm{H}_{2} \mathrm{O}$ in Juan de Fuca ridge basaltic glasses. Earth and Planetary Science Letters, 90, 87-104. doi:10.1016/0012-821X(88)90114-8

[16] Clague, D., Davis, A. and Dixon, J. (2003) Submarine strombolian eruptions on the Gorda Mid-Ocean Ridge. In: White, J.D.L., Smellie, J. and Clague, D., Eds., Explosive Subaqueous Volcanism, AGU Geophysical Monograph, Washington DC, 111-128. doi:10.1029/140GM07

[17] Friedman, P.D., Vadakoot, V., Meyer, W.J. and Carey, S. (2007) Instability threshold of a negatively-buoyant fountain. Experiments in Fluids, 42, 751-759. doi:10.1007/s00348-007-0283-5

[18] Friedman, P.D., Meyer, W.J. and Carey, S. (2006) The fluid dynamics of phase mingling in a subaqueous volcanic eruption-An experimental investigation. Journal of Geophysical Research—Solid Earth, 111, B07201

[19] Friedman, P.D., Winthrop, A.L. and Katz, J. (2001) Droplet, formation and size distributions from an immiscible interface impinged with a vertical negatively buoyant jet. Atomization and Sprays, 11, 269-290.

[20] Friedman, P.D. and Katz, J. (2000) Rise height for negatively buoyant fountains and depth of penetration for negatively buoyant jets impinging on an interface. Journal of Fluids Engineering, 122, 779-782. doi:10.1115/1.1311786

[21] Llewellin, E. and Manga, M. (2005) Bubble suspension rheology and implications for conduit flow. Journal of Volcanology and Geothermal Research, 143, 205-217. doi:10.1016/j.jvolgeores.2004.09.018

[22] Büttner, R. and Zimanowski, B. (1998) Physics of thermohydraulic explosions. Physical Review E, 57, 5726-5729.

[23] Manga, M. and Loewenberg, M. (2001) Viscosity of magmas containing highly deformable bubbles. Journal of Volcanology and Geothermal Research, 105, 19-24. doi:10.1016/S0377-0273(00)00239-0

[24] Desjardins, O., Blanquart, G., Balarac, G. and Pitsch, H. (2008) High order conservative finite difference scheme for variable density low Mach number turbulent flows. Journal of Computational Physics, 227, 7125-7159. doi:10.1016/j.jcp.2008.03.027

[25] Desjardins, O., Moureau, V. and Pitsch, H. (2008) An accurate conservative level set/ghost fluid method for simulating turbulent atomization. Journal of Computational Physics, 227, 8395-8416. doi:10.1016/j.jcp.2008.05.027

[26] Desjardins, O. and Pitsch, H. (2009) A spectrally refined interface approach for simulating multi-phase flows. Journal of Computational Physics, 228, 1658-1677. doi:10.1016/j.jcp.2008.11.005

[27] Raessi, M. and Pitsch, H. (2012) Consistent mass and momentum transport for simulating incompressible interfacial flows with large density ratios using the level set method. Computers and Fluids, 63, 70-81. doi:10.1016/j.compfluid.2012.04.002

[28] Kang, M., Fedkiw, R. and Liu, X.-D. (2000) A boundary condition capturing method for multiphase incompressible flow. Journal of Scientific Computing, 15, 323-360. doi:10.1023/A:1011178417620

[29] Wilson, L. and Head, J. (1981) Ascent and eruption of basaltic magma on the Earth and Moon. Journal of Geophysical Research, 86, 2971-3001. doi:10.1029/JB086iB04p02971

[30] Allen, S., Fiske, R. and Cashman, K. (2008) Quenching of steam-charged pumice: Implications for submarine pyroclastic volcanism. Earth and Planetary Science Letters, 274, 40-49. doi:10.1016/j.epsl.2008.06.050

[31] Siebe, C., Komorowski, J.C., Navarro, C., McHone, J., Delgado, H. and Cortes, A. (1995) Submarine eruption near Socorro Island, Mexico: Geochemistry and scanning electron microscopy studies of floating scoria and reticulite. Journal of Volcanology and Geothermal Research, 68, 239271. doi:10.1016/0377-0273(95)00029-1

[32] Whitham, A. and Sparks, R.S.J. (1986) Pumice. Bulletin of Volcanology, 48, 209-223. doi:10.1007/BF01087675 